\title{
Widening the View on Teacher-Child Relationships: Teachers' Narratives Concerning Disruptive Versus Nondisruptive Children
}

\author{
Jantine L. Spilt and Helma M.Y. Koomen \\ University of Amsterdam
}

\begin{abstract}
The goal of the present study was to obtain evidence for the validity of the Teacher Relationship Interview by exploring associations with a well-validated measure of teacher-child relationship quality, the Student-Teacher Relationship Scale (Closeness, Conflict, and Dependency), and examining differences between teachers' narratives about the relationship with a disruptive and a nondisruptive child in their class. Six constructs were derived from teachers' narratives $(N=90)$ that were elicited with the Teacher Relationship Interview: sensitive practices, positive affect, helplessness, anger, neutralizing negative affect, and coherence. Multilevel analyses showed moderate convergence between the Student-Teacher Relationship Scale and the Teacher Relationship Interview. Expressed anger was related to relational conflict, whereas positive affect and low levels of helplessness appeared associated with close relationships. The coherence of the narrative and the tendency to neutralize negative emotions were positively associated with conflict. No unique associations were found with teachers' narrated sensitive practices. Furthermore, anger and helplessness appeared more prominent in narratives about relationships with disruptive children.
\end{abstract}

Developmental scholars and school psychologists increasingly adopt a relational perspective to understand children's development within the school context. Accumulating evidence demonstrates that warm and open teacher-child relationships foster children's socialemotional and academic functioning, whereas high levels of conflict and discordance hamper children's development (e.g., Baker, 2006; Hamre \& Pianta, 2001; Ladd \& Burgess, 2001; O'Connor \& McCartney, 2007; Palermo, Hanish, Martin, Fabes, \& Reiser, 2007; Pianta, Steinberg, \& Rollins, 1995; Pianta \& Stuhlman, 2004). From the perspective of the teacher, poor teacher-child relationships have been related to low levels of competence and job satisfaction, and high levels of teaching stress (Koomen, Verschueren, \& Pianta, 2007). Together, these findings suggest that favorable teacher-child relationships contribute to the well-being of both teachers and children. However, evidence is mainly based on research that has employed teacher report questionnaires. In the present study, we aimed to widen the view on teacher-child relationships by eliciting information from teachers through semistructured interviews. Furthermore, we focused on relationships with dis-

Correspondence regarding this article should be addressed to Jantine L. Spilt, Department of Education, Faculty of Social and Behavioral Sciences, University of Amsterdam, P.O. Box 94208, 1090 GE Amsterdam, the Netherlands; E-mail: j.1.spilt@uva.nl

Copyright 2009 by the National Association of School Psychologists, ISSN 0279-6015 
ruptive children because children at risk of maladaptive development are especially sensitive to teacher-child relationship quality (e.g., Burchinal, Peisner-Feinberg, Pianta, \& Howes, 2002; Meehan, Hughes, \& Cavell, 2003; Silver, Measelle, Armstrong, \& Essex, 2005; Hughes, Cavell, \& Jackson, 1999).

\section{Assessment of Teacher-Child Relationship Quality}

The Student-Teacher Relationship Scale (STRS; Pianta, 2001) is the most widely used scale to assess teacher perceptions of relationships with students in primary education. This scale contains the dimensions of closeness (i.e., warmth and open communication), conflict (i.e., discordant interactions), and dependency (i.e., overly dependent and clingy child behavior), and has proven a valuable measure of relationship quality. The conflict dimension in particular appears to be a salient characteristic of relationships with disruptive children. Children with externalizing behavior are at risk for vicious cycles of increasingly conflictual interactions that, in turn, jeopardize their subsequent school trajectories (e.g., Doumen, Verschueren, Buyse, Germeijs, Luyckx, \& Soenens, 2008; Ladd \& Burgess, 2001). On the other hand, it has been found that emotional support and closeness function as protective factors for children with behavior problems (e.g., Ladd \& Burgess, 2001; Meehan et al., 2003; Silver et al., 2005). These findings are important for school psychologists and other practitioners who are interested in the prevention of children's behavior problems. Koomen, Verschueren, and Thijs (2006) discussed available measures of affective qualities of teacher-child relationships that are valuable in practice-oriented research. They considered the Teacher Relationship Interview (TRI) an instrument with high potential for both scientists and practitioners. The TRI (Pianta, 1999a) is a relationship-focused interview that explores aspects of teachers' professional roles such as sensitivity of socializing and emotional support, and affective experiences with a particular student (see Appendix for descriptions of the constructs mea- sured with the TRI). Whereas the STRS is most useful as a screening measure to identify relational difficulties or strengths, Koomen and colleagues (2006) argued that the TRI offers a more differentiated picture that can be particularly useful as a starting point for relationship-focused consultation with teachers. However, what is needed first is empirical research that demonstrates the validity of the TRI.

\section{Interview-Based Methods in Relationship-Focused Research}

Another reason to study the utility of interview-based methods such as the TRI is the postulate that teachers develop internal working models of their relationships with students. Teacher-child relationships are conceptualized as dyadic systems that are not only affected by actual behaviors and qualities of the partners but also by each individual's mental representation of the relationship (Pianta, Hamre, \& Stuhlman, 2003). The postulate that each individual's perspective of the teacherchild relationship can be viewed as a representational model is largely guided by attachment theory (Bowlby, 1969/1982; Bretherton, 1985). An important claim of attachment theory is that these models tend to operate outside conscious awareness. Whereas questionnaires seem to tap mainly cognitions, there is evidence that interview techniques are more suitable to capture unconscious operating processes (Maier, Bernier, Perkrun, Zimmermann, \& Grossmann, 2004). Representational measures may provide additional insight into teacher-child relationships and highlight more implicit qualities such as emotional processes.

Mental representations or internal working models are conceptualized as sets of internalized feelings and cognitions that guide expectations and behaviors toward others in a consistent and predictable manner (Bowlby, 1969/1982; Bretherton, 1985). Children construct internal working models of self and significant others based on their experiences with attachment figures. These models are constructed as postulates about the "self" as 
worthy, the "other" as accepting and reliable, and the degree of security provided by the "self-other relationship." Internal working models are thought to guide children's attachment behaviors, with the main goal of maintaining security. Research into mother-child relationships has demonstrated that caregiving as a set of parenting behaviors is organized at the level of representations as well. The set goal of the caregiving behavioral system may be conceptualized as providing protection and security for the child (George \& Solomon, 1996). It contains beliefs about the self as a caregiver, effectiveness of caregiving strategies, and evaluations of the child's needs (George \& Solomon, 1996; Solomon \& George, 1999). Analogously, it is postulated that teachers' representational models of the teacher-child relationship contain expectations and beliefs about the self as a teacher, about various roles (e.g., caregiver, disciplinarian, and instructor), and about how children relate to teachers, based on teachers' own experiences as a teacher and of being taught and parented themselves (Pianta, 1999b). Furthermore, the teaching behavioral system may be organized around the central goal of fostering a child's development. To tap into adults' representational models of interpersonal relationships, researchers generally use interview techniques (e.g., Adult Attachment Interview-Main, Kaplan, \& Cassidy, 1985; Parent Attachment Interview-Bretherton, Biringen, Ridgeway, Maslin, \& Sherman, 1989; Parent Development Interview-Button, Pianta, \& Marvin, 2001). Three main dimensions have been postulated in the literature to effectively evaluate representational models from interview data (Button et al., 2001): The first concerns the content of representations and is reflected in "what" is narrated during the interview. Several domains of content are suggested that reflect views and beliefs about various roles (i.e., secure base, sensitivity of socializing). Secondly, the processing of information is considered a central dimension referring to "how" represented information is admitted or denied. Dysfunctional processing may be reflected in reluctance or preoccupation with certain themes or low coherence of the narrative. Finally, it is conceived that representational models contain an affective dimension. In maternal narratives, representations of negative affective experiences (i.e., worry and enmeshment) appeared especially related to mothers' behavior (Button et al., 2001).

The TRI is based on a similar conceptual and methodological approach as employed in parent-child research (Pianta, 1999a). Stuhlman and Pianta (2002) examined the narratives of 50 teachers elicited with the TRI in relation to observed teacher-child interactions in kindergarten and first grade. In line with the parenting literature (e.g., George \& Solomon, 1996; Solomon \& George, 1999), their results primarily revealed the significance of teachers' negative emotional processes in relationship with a specific student. Teachers' expressions of negative affect were positively associated with observed displays of negativity by both the child and teacher. In addition, teachers' expressions of positive affect appeared positively related to children's displays of positive affect and negatively to observed noncompliance. How teachers processed information related to negative experiences (i.e., their inclination to neutralize negative affect) was negatively related to children's observed compliance but not to observed teacher practices. Regarding the content of the interview, only the mentioning of compliance issues in the narrative was negatively related to teachers' observed displays of positive affect. Together, the results supported the validity of the TRI as a measure of relationship quality. To obtain further evidence, it is critically important to examine the convergence with other well-validated measures of relationship quality such as the STRS.

\section{Overview of Present Study and Hypotheses}

We argue that representational measures such as interviews offer an additional window to gain insight into teachers' feelings, beliefs, and expectations in relationships with particular students who could not be captured by other measures such as questionnaires or ob- 
servations (Stuhlman \& Pianta, 2002). Information derived from teachers' narratives elicited with the TRI is presumed to advance understanding of teachers' relational experiences with children at risk for behavior difficulties, and has potential for practice-oriented assessment and teacher consultation (Koomen et al., 2006). The main goal of the current study was to obtain empirical support for the TRI as an adequate tool in relationship-focused research and practice. To establish evidence for the validity of the TRI, teachers' relationship narratives should be meaningfully related to teacher reports on the STRS and vary as a function of children's externalizing behavior.

For several reasons, the study was conducted in kindergarten: The extended attachment perspective has primarily been employed in early teacher-child relationships, and young at-risk children appear to be especially sensitive to relationship quality. As one of the first studies using relationship-focused narratives to assess teacher-child relationship quality, the nature of the study was largely descriptive and exploratory. Our first aim was to examine convergence between the STRS and the TRI. Although both instruments measure affective qualities of teacher-child relationships, they assess somewhat different constructs and employ different methods. Therefore, we expected only moderate convergence. No hypotheses could be stated about associations between specific subscales because of lack of previous research. The second aim was to study differences between disruptive versus nondisruptive children in teachers' narratives. Because teachers generally report more conflict on the STRS for children with externalizing behavior, we expected higher means on the negative scales of the TRI (i.e., Anger, Helplessness, and Neutralizing Negative Affect) for teacher-child relationships involving disruptive children. In addition, we explored differences in associations between teachers' narratives (TRI) and self-reports (STRS) for disruptive versus nondisruptive children (i.e., moderating effects), without testing specific hypotheses.
Although this study is focused on dyadic relationships, it is possible that teachers' narratives are to some degree driven by teacher characteristics. Understanding the extent to which narratives reflect teacher effects could have important implications for the interpretation of the findings. Therefore, as an additional goal, we examined the proportion of variance that could be attributed to teacher effects. We anticipated that a minority of variance could be attributed to teacher characteristics. This expectation is in line with the postulation of Pianta and colleagues (2003), who argued that teachers' mental representations should be conceived as higher order constructs that mainly embody properties of the dyadic relationship.

\section{Method}

\section{Participants and Procedures}

Sample. The sample included 90 kindergartners (46 boys) from 48 kindergarten classes of 23 regular elementary grade schools in the Netherlands. The mean age of the children was 69.5 months $(S D=5.0)$. In Dutch schools, kindergarten starts when children are 4 years old and lasts for 2 years, so most children had already spent about 1 year with the same teacher. Teachers $(N=48$; one male) were on average 43 years old $(S D=11.1)$ and had 15.5 years $(S D=11.8)$ of teaching experience. The majority of teachers $(84.1 \%)$ worked 3 days or more per week $(M=3.9, S D=1.0)$. Informed consent was obtained from the parents.

Selection. Children and teachers participated in a larger research project that aimed to assess the teacher-child relationship from the perspectives of both teachers and students in kindergarten. Because using child instruments required understanding of the Dutch language, schools had been selected that predominantly served students with a Dutch ethnicity. Furthermore, children were included only if they had attended the same class for at least 2 months and were at least 5 years old.

For the present study, a disruptive and a nondisruptive target child were selected in 
Table 1

Means and Standard Deviations of the BQTSYO-M, TRI, and STRS in the Nonexternalizing $(n=44)$ and Externalizing Subgroups $(n=46)$

\begin{tabular}{|c|c|c|c|c|c|}
\hline & \multicolumn{2}{|c|}{ Nonexternalizing } & \multicolumn{2}{|c|}{ Externalizing } & \multirow[b]{2}{*}{$t$ Value } \\
\hline & $M$ & $S D$ & $M$ & $S D$ & \\
\hline \multicolumn{6}{|l|}{ BQTSYO-M } \\
\hline Externalizing & 1.20 & 0.15 & 1.94 & 0.42 & $-15.131 * *$ \\
\hline Internalizing & 1.15 & 0.16 & 1.20 & 0.16 & -1.773 \\
\hline \multicolumn{6}{|l|}{ TRI } \\
\hline Sensitive Practices & 4.83 & 0.81 & 4.86 & 0.70 & -0.637 \\
\hline Positive Affect & 4.77 & 1.26 & 4.64 & 1.06 & 0.500 \\
\hline Helplessness & 2.53 & 0.93 & 2.92 & 0.94 & $-1.979 *$ \\
\hline Anger & 2.09 & 1.06 & 2.94 & 1.28 & $-3.105^{* *}$ \\
\hline Neutralizing & 3.04 & 1.04 & 2.73 & 1.04 & 1.245 \\
\hline Coherence & 3.91 & 0.66 & 4.00 & 0.55 & -0.647 \\
\hline \multicolumn{6}{|l|}{ STRS } \\
\hline Closeness & 4.41 & 0.56 & 4.27 & 0.69 & 0.593 \\
\hline Conflict & 1.53 & 0.68 & 2.39 & 1.00 & $-4.237 * *$ \\
\hline Dependency & 1.97 & 0.78 & 2.33 & 0.79 & $-2.259 *$ \\
\hline
\end{tabular}

Note. BQTSYO-M = Behavior Questionnaire for Two- to Six-Year-Olds-Modified; TRI = Teacher Relationship Interview; STRS = Student-Teacher Relationship Scale.

$* p<.05$.

$* * p<.01$.

each class. The selection was based on teacher reports of externalizing and internalizing behavior on a short behavior checklist that will be described in the Instruments section (i.e., Behavior Questionnaire for Two- to Six-YearOlds-Modified, or BQTSYO-M). In general, the child who received the highest rating for externalizing behavior was selected for the externalizing group. For the nonexternalizing group, the child with the lowest score for externalizing behavior was selected. Children of the same sex were selected in each classroom to avoid gender bias. However, this was not possible in five classes. Furthermore, in both groups, only children were included with scores below $1 S D$ above the mean on internalizing behavior obtained from a convenience sample $(N=2,040)$. Teachers were not informed about the selection criteria. Because externalizing behavior was distributed differently across classes, the scores of the externalizing subgroup covered almost the full-scale range (1.14-3.00) and reflected a normal distribution (kurtosis $=-0.44$, skewness $=0.34$; see also Table 1).

Data collection. Teachers completed two questionnaires for at least 12 children in their class and were interviewed about their relationship with the two selected target children. To reduce workload, short questionnaires were administered (i.e., the BQTSYO-M and a shortened version of the STRS described in the Instruments section). Data collection proceeded in three steps. The behavior checklist was administered first to select the two target children. Next, interviews were conducted. Finally, teachers completed the STRS.

Interviews with the teacher were conducted by trained undergraduate students from the Department of Education during late winter and spring of the school year. Teachers were interviewed separately about each child after school time in a private setting in their 
schools. The order of the interviews was counterbalanced across teachers by starting randomly with either the child from the externalizing or nonexternalizing subgroup. Teachers were informed about the target child only just before the start of the interview. Interviews took about $30 \mathrm{~min}$. For the purpose of coding, all interviews were audiotaped.

Missing data. At the start, a total of 96 children participated in the study. However, one teacher only provided information about 1 student (a girl selected for the externalizing group). For 3 children (all boys, 2 from the externalizing subgroup), teachers did not return the STRS. In addition, 2 children (both girls from the nonexternalizing subgroup) were selected with relatively high scores on internalizing behavior $(>1 S D)$ because of a miscommunication; they were excluded from the analyses. The data set was complete for 44 children (21 boys) in the nonexternalizing group and 46 ( 25 boys) in the externalizing group; the presented results pertain only to these 90 children.

\section{Instruments}

Behavior checklist. Teachers completed the BQTSYO-M (Thijs, Koomen, De Jong, Van der Leij, \& Van Leeuwen, 2004). The BQTSYO-M is a short screening instrument that aims to measure teachers' perceptions of internalizing and externalizing problems and is specifically developed for young children. The questionnaire is derived from the Preschool Behavior Questionnaire, which is a widely used scale in international research (Behar, 1977). Items are rated on a 4-point Likert scale, ranging from 1 (absolutely not characteristic) to 4 (very characteristic). In the present study, the broad-band internalizing scale (15 items; e.g., "Shy or timid towards other children," "Easily upset") and externalizing scale (14 items; e.g., "Bullies other children," "A busy child") were used. Previous research has reported adequate interrater agreement between teachers (Cronbach's alpha values of .94 and .86 for the Externalizing and Internalizing scales, respectively), and significant associations with subscales of the
Child Behavior Checklist in the expected directions (Goossens, Dekker, Bruinsma, \& De Ruyter, 2000). Furthermore, the measure has been successfully employed in research into social processes and teacher-child relationships (Goossens, Bokhorst, Bruinsma, \& Van Boxtel, 2002; Thijs, Koomen, \& Van der Leij, 2006, 2008). Those previous studies have reported high internal consistencies with Cronbach's alpha, ranging between .81-.90 and .91-.93, respectively, for the Internalizing and Externalizing scale. In the current sample, alpha coefficients of .75 for the Internalizing and .92 for the Externalizing scale were found.

\section{Teacher reports of relationship qual-} ity. The STRS (Pianta, 2001) aims to measure teachers' perceptions of the relationship with a particular student. In the present study, an authorized Dutch translated and adapted version of the STRS was employed (Koomen et al., 2007). The scale comprises three dimensions, labeled closeness (e.g., "I share an affectionate, warm relationship with this child"), conflict (e.g., "This child and I always seem to be struggling with each other"), and dependency (e.g., "This child asks for my help when he/she really does not need help"). Closeness reflects the degree of warmth and open communication between the teacher and child. Conflict refers to negative and coercive teacher-child interactions, whereas dependency represents levels of clinginess and overdependence of the child. Items are rated on a 5-point scale ranging from 1 (not at all applicable) to 5 (highly applicable). The subscales Closeness and Conflict in the Dutch adaptation were highly comparable with the original STRS scales. The Dependency scale was altered because of its marginal internal consistency in prior research $(\alpha=.55-.67$; Pianta, 2001). One original item was removed because of a factor loading below .40 (e.g., "This child appears hurt or embarrassed when I correct him/her"), and two new items were added (i.e., "This child fixes his/her attention on me the whole day long"; "This child needs to be continually affirmed by me"). Previous studies using the Dutch STRS have reported adequate psychometric properties (Doumen, Verschue- 
ren, \& Buyse, 2008, Koomen et al., 2007). Internal consistency scores ranged between .88 and .93 for Closeness, .88 and .91 for Conflict, and .75 and .82 for Dependency. Stability coefficients at three measurement occasions during the same school year indicated relatively high stability (Closeness .73-.84; Conflict. 74-.83; Dependency .67-.77). Its validity has been demonstrated in relation to observed relationship quality, teacher stress indices, children's social-emotional functioning, and behavioral engagement from teacher, parent, and observer reports. In the present study, a shortened version was used comprising the 5 items with the highest factor loadings per subscale. Cronbach's alpha coefficients were $.78, .86$, and .75 , respectively, Closeness, Conflict, and Dependency in the current sample.

Relationship interview. The TRI is a semistructured interview that aims to assess teachers' internal representations of the relationship with a particular student (Pianta, 1999a). In the present study, a more recent version was used that was obtained from the author by e-mail in 2003 . The current version contained 12 questions referring to the relationship with the child. Teachers were first asked to indicate three adjectives describing their relationship with the child and provide evidence for the choice of these adjectives. The subsequent questions concerned negative and positive experiences and asked the teacher to describe examples of interpersonal moments, such as "Describe a time in the last week when you and your child really clicked." Teachers were also asked about typical situations relating to various teacher roles, "Can you tell about a situation when the child displayed serious misbehavior?" They were further requested to support their statements with real-life examples and probed to be as specific as possible. Standard follow-up questions were presented regarding the emotional states of the teacher and the child during the described interaction.

Nine constructs were coded with respect to three areas. The content area included the scales Sensitivity of Discipline, Secure Base, and Agency/Intentionality. The affect area included Helplessness, Anger/Hostility, and Positive Affect. Finally, the process area comprised the scales Perspective Taking, Neutralizing of Negative Affect, and Coherence. Detailed descriptions of the constructs are provided in the Appendix. The interview was examined as a whole. Qualitative ratings were given on a 7-point scale; only the coherence of the narrative was rated on a 5-point scale. Coders were trained until sufficient interrater agreement was established. Two raters out of a pool of six independent raters scored each interview in a random order. The average score was used in the analyses. When large rating differences were observed (i.e., $>2$ ), a third coder independently rated the interview to establish the most appropriate score. Raters were not familiar with the teacher, the child, or the behavioral status of the child. However, for $23(25.6 \%)$ interviews, a student who had conducted the interviews provided one of the ratings.

To reduce the number of variables, associations among the subscales were explored. A series of principal component analyses and exploratory factor analyses (maximum likelihood) on all interview scales were conducted in both the externalizing and nonexternalizing subgroup. Results indicated a factor containing the scales Sensitivity of Discipline, Secure Base, Perspective Taking, and Intentionality that was similar in both subgroups (factor loadings $\geq 0.72$ ). Accordingly, a new scale was constructed that was labeled Sensitive Practices $(\alpha=.86-.89)$. High scores indicated awareness of the student's social-emotional and academic needs and clear statements of sensitive and child-centered pedagogical practices. Although Perspective Taking was a priori considered an indicator of how teachers process information, it does fit with the content scales because awareness of children's inner states is a prerequisite for tuning behavioral-emotional support to the special needs of individual children. This finding is in line with results from (unpublished) dissertation research (Zeller, 2004). The other scales were treated as separate constructs because no fac- 
Table 2

Correlations Between Scales of TRI and STRS in Nonexternalizing ( $n=44$; Below Orthogonal) and Externalizing Subgroups

$(n=46 ;$ Above Orthogonal)

\begin{tabular}{lccccccccc}
\hline \multicolumn{1}{c}{ Scale } & 1 & 2 & 3 & 4 & 5 & 6 & 7 & 8 & 9 \\
\hline TRI & & & & & & & & & \\
1. Sensitive Practices & - & $.43^{* *}$ & $-.32^{*}$ & -.02 & $-.32^{*}$ & $.53^{* *}$ & .02 & $.28^{*}$ & -.06 \\
2. Positive Affect & $.74^{* *}$ & - & $-.51^{* *}$ & -.21 & $-.50^{* *}$ & $.25^{*}$ & $.30^{*}$ & -.01 & .02 \\
3. Helplessness & $-.42^{* *}$ & $-.27^{*}$ & - & $.53^{* *}$ & -.12 & -.05 & $-.27^{*}$ & .24 & .01 \\
4. Anger & -.24 & -.07 & $.33^{*}$ & - & -.01 & $.26^{*}$ & .00 & $.34 * *$ & .13 \\
5. Neutralizing & $-.54^{* *}$ & -.23 & .15 & $-.49^{* *}$ & - & $-.58^{* *}$ & .18 & -.26 & .19 \\
6. Coherence & $.68^{* *}$ & $.52^{* *}$ & $-.26^{*}$ & -.06 & $-.38^{* *}$ & - & .03 & $.43^{* *}$ & .04 \\
STRS & & & & & & & & & \\
7. Closeness & $.39^{* *}$ & $.40^{* *}$ & $-.56^{* *}$ & -.18 & -.01 & .19 & - & $-.34^{*}$ & .14 \\
8. Conflict & .07 & -.07 & .06 & $.28^{*}$ & .24 & .14 & -.08 & - & $.26 *$ \\
9. Dependency & $.30^{*}$ & .19 & -.11 & -.02 & -.17 & .21 & .15 & $.35^{*}$ & - \\
\hline
\end{tabular}

Note. TRI $=$ Teacher Relationship Interview; STRS $=$ Student-Teacher Relationship Scale.

$* p<.05$ (one tailed).

$* * p<.01$ (one tailed).

tor patterns emerged that were equivalent across subgroups.

To assess interrater agreement, intraclass correlations (ICCs) were calculated based on the average measure. ICCs are measures of the proportion of variance accounted for by between-subject differences. Low ICCs suggest that a substantial proportion of variances could be attributed to rater effects, thereby reflecting poor interrater reliability. ICCs between 0.75 and 1.00 indicate excellent agreement; ICCs between 0.60 and 0.74 indicate good agreement; and ICCs between 0.40 and 0.59 are considered fair (Cicchetti et al., 2006). Good to excellent agreement was obtained for Helplessness, Sensitive Practices, Positive Affect, and Negative Affect (ICCs of 0.64, 0.68, 0.75, and 0.82 , respectively). For Coherence, little variance in scores was observed, which most likely accounts for the relatively low ICC of 0.50. Closer inspection revealed a proportion of $90 \%$ agreements within one scale point. For Neutralizing Negative Affect, an ICC of 0.51 was found, which indicated fair interrater reliability.

\section{Results}

\section{Preliminary Analyses}

Group selection. First, we examined whether the selection procedure had been successful. Table 1 presents the descriptive statistics of externalizing and internalizing behavior and the results of paired $t$ tests. Higher scores on externalizing behavior were found for the externalizing group compared to the nonexternalizing group. No differences emerged on internalizing behavior.

Descriptive statistics and intercorre-

lations. Table 1 presents means and standard deviations of the relationship variables for the nonexternalizing and externalizing subgroups. Correlations between the continuous variables are presented in Table 2 for each subgroup. In the nonexternalizing group, Closeness was positively related to Sensitive Practices and Positive Affect, and negatively related to Helplessness. Conflict correlated positively with Anger. Lastly, a positive association appeared between Dependency and Sensitive Practices. In the externalizing group, a some- 


\section{Table 3}

\section{Final Regression Models Predicting Teacher Reports of Relationship Quality $(N=90)$}

\begin{tabular}{lccc}
\hline \multicolumn{1}{c}{ Variable } & Closeness $B(S E)$ or $\Delta R^{2}$ & Conflict $B(S E)$ or $\Delta R^{2}$ & Dependency $B(S E)$ or $\Delta R^{2}$ \\
\hline Intercept & $4.33(.07)^{* *}$ & $1.64(.12)^{* *}$ & $1.95(.11)^{* *}$ \\
Step 1 predictors & - & $19.5 \%$ & $6.0 \%$ \\
Externalizing & - & $.66(.17)^{* *}$ & $.39(.16)^{* *}$ \\
Step 2 predictors & $39.9 \%$ & $18.9 \%$ & - \\
Sensitive Practices & - & - & - \\
Positive Affect & $.15(.06)^{* *}$ & - & - \\
Helplessness & $-.19(.06)^{* *}$ & - & - \\
Anger & - & $.30(.09)^{* *}$ & - \\
Neutralizing & - & $.30(.10)^{* *}$ & - \\
Coherence & - & & \\
\hline
\end{tabular}

Note. Unstandardized regression coefficients $(B)$ are presented.

$* p<.05$ (one tailed).

$* * p<.01$ (one tailed).

what different pattern of associations emerged. Closeness was positively related to Positive Affect and negatively related to Helplessness. Furthermore, Conflict was positively associated with Sensitive Practices, Anger, and Coherence. No significant associations with Dependency were observed in the externalizing subgroup.

\section{Between-Group Differences}

Mean differences were examined on the TRI and STRS scales for the nonexternalizing versus the externalizing subgroup (see Table 1). Teachers reported significantly more conflict and dependency for the externalizing than the nonexternalizing subgroup. Furthermore, they expressed more anger and helplessness in their narratives concerning children from the externalizing group.

\section{Regression Models}

Linear regression models were examined using MLwiN Version 2.02 (Rasbash, Browne, Healy, Cameron, \& Charlton, 2005) to assess the unique associations between reported relationship quality, interview variables, and externalizing group. For all three outcome variables (i.e., closeness, conflict, and dependency), two-level random intercept models were estimated with children (Level 1) nested within teachers (Level 2). Externalizing group was included as a dummy variable $(0=$ nonexternalizing subgroup, 1 = externalizing subgroup). The TRI scales were transformed into $z$ scores to facilitate interpretation. Teacher variables (age, experience, and days of employment) were included as covariates (Level 2 predictors), but none of these were significant $(p>.05)$ in the final models and therefore not reported. Because gender of the child was controlled for in the selection procedure, it was not included in the analyses. All predictors were entered into the model at the child level (Level 1) as fixed effects (i.e., variance terms were fixed to 0 ). First, to control for between-group differences, externalizing group was added into the equation. In the second step, interview variables were simultaneously entered as predictors. Nonsignificant predictors were removed from the equation. The final models are presented in Table 3.

The results showed main effects of positive affect and helplessness on Closeness in the expected directions. Furthermore, representations of anger, neutralizing negative affect, and coherence had unique positive effects on Conflict. However, the externalizing group 
appeared as the strongest predictor of Conflict. Lastly, for Dependency, only externalizing group emerged as a significant predictor.

Residuals were inspected to detect outliers and to verify the assumptions of normality and homoscedasticity. The homoscedasticity assumption was violated in the prediction of Conflict. Reanalyses of the model in each subgroup separately showed no violations in the externalizing group and yielded virtually the same results as those presented in Table 3. This suggests that the model of Conflict applies well to children with externalizing problems but should be interpreted with caution for nonproblem children.

Moderation effects. Because somewhat different correlation patterns were observed across subgroups, interactions between externalizing group and interview variables could be expected. Interaction terms were computed by multiplying the standardized interview variables with externalizing group (dummy). The addition of interaction terms did not significantly improve the models (Closeness: $\Delta \chi^{2}=3.27, \Delta d f=6, p>.05$; Conflict: $\Delta \chi^{2}=5.91, \Delta d f=6, p>.05$; Dependency: $\Delta \chi^{2}=7.85, \Delta d f=6, p>.05$ ).

\section{Teacher Effects in the Narratives}

ICCs measure the proportion of total variance that can be attributed to betweensubject variance (i.e., differences between teachers). It was found that a substantial proportion of the variance in sensitive practices (ICC $=0.44, p<.01$ ) and neutralizing negative affect $(\mathrm{ICC}=0.57, p<.01)$ could be attributed to teacher effects. For the other interview variables, no significant intraclass correlations emerged, suggesting that the variances could be attributed to differences between relationships with a disruptive versus average child.

\section{Discussion}

The main goal of this study was to provide support for the validity of the TRI as a measure of teacher-child relationship quality. Guided by attachment research and the par- ent-child literature, it was assumed that interview techniques could reveal properties of teacher-child relationships that may not be captured with other means such as questionnaires. We presumed that the TRI would be a valuable instrument to assess strengths and difficulties in teachers' relationships with specific students, knowledge that is beneficial to both scholars and practitioners. To establish support for the validity of the TRI, we examined convergence with a well-validated teacher report questionnaire (STRS) and differences between teachers' relationships with typically developing versus disruptive children. Relationship interviews were coded for six constructs representing three main dimensions: content, affect, and processing of information. Consistent with previous research (Stuhlman \& Pianta, 2002), the results generally confirmed that the TRI is a valuable tool to advance understanding of teachers' affective experiences and processing of information in relationships with young students. In particular, negative affective qualities appeared related to children's behavior problems.

The first aim was to examine convergence between teachers' narratives and questionnaire reports of relationships with individual pupils. In line with our expectations, moderate convergence was found. Teachers' expressions of anger were positively associated with relational conflict. In contrast, positive affect appeared exclusively related to closeness. This corroborates that teacherchild relationships embody two relatively independent dimensions: a positive dimension reflecting closeness, warmth, and positive affect, and a negative dimension reflecting discordance, anger, and difficulties in modulation of negative experiences (Pianta, 2001). Surprisingly, helplessness accounted for variance in closeness, but not conflict. This finding suggests that nonclose relationships evoke feelings of ineffectiveness and discourage teachers from investing in the child or searching for new strategies to assert influence. Analogously, other researchers have also postulated that teachers may experience failure in their attempts to form close relationships and are inclined to estimate the cost-benefit ratio 
related to their interpersonal investment and the expected "emotional return" (e.g., Hargreaves, 2000; Newberry \& Davis, 2008).

Teachers' processing of information was also related to relationship quality. A positive association emerged between the coherence of the narratives and relational conflict. Although this may appear counterintuitive, it could be argued that recurrent interpersonal conflicts force teachers to actively deal with the child. Many daily interactions may make it easier for teachers to support their statements with adequate and recent examples, thereby providing an understandable and coherent picture of the dyadic relationship. In contrast, children who are rarely involved in conflicts could be easily overlooked because they demand considerably less attention from teachers. This may be reflected in less coherent narratives. It is noteworthy, however, that most teachers were able to provide a fairly coherent picture of their relationship with a particular student. With respect to neutralizing of negative affect, teachers appeared to shy away from discussing negative emotions in conflictual relationships. This association was only found when anger and coherence were included in the model, which indicates a suppression effect. In line with this finding, Newberry and Davis (2008) contended that, in some dyads, teachers tend to emotionally distance themselves by acting "professional" (i.e., suppressing negative feelings) in order to control conflict. However, research suggests that students are aware of teachers' negative affect despite teachers' attempts to be supportive in this manner (Babad, 1990).

Despite several zero-order correlations, the content of teachers' narratives (i.e., sensitive practices) was not uniquely related to their reports of relationship quality. In previous research with the TRI, relatively modest evidence also was found for the importance of the content of the narratives (Stuhlman \& Pianta, 2002). Thus what is narrated may be less important than how the information is processed and the affective quality of this information. It should be noted that our findings with respect to relational conflict apply mainly to children with disruptive behaviors. The model of con- flict was less appropriate for nonproblem children.

The second aim of the present study was to explore differences in teachers' relationship narratives about disruptive versus nondisruptive children. To properly interpret these findings, it is noteworthy that children were selected based on teachers' perceptions of externalizing behavior and not on actual behavior problems. As expected, teachers expressed more anger and helplessness concerning the child they perceived as most disruptive in their class as compared to a nondisruptive child. In addition, more conflict and dependency were reported for disruptive children. These findings are consistent with research that has shown higher levels of relational negativity for children with problem behavior (Birch \& Ladd, 1998; Hamre, Pianta, Downer, \& Mashburn, 2008; Ladd \& Burgess, 1999; Murray \& Murray, 2004). On the other hand, teachers expressed similar levels of positive affect in narratives about disruptive children versus nondisruptive children, and also reported similar levels of closeness. This suggests that the two groups did not differ on positive aspects of the teacher-child relationship. In line with this, previous research has consistently indicated strong associations between externalizing problems and conflict but much smaller associations with closeness (Murray \& Murray, 2004; Palermo et al., 2007; Pianta \& Stuhlman, 2004). It appeared to us that the nonexternalizing group included a number of "overlooked" students about which teachers had very little to say in the interviews and for whom they had neither positive nor negative feelings. This is supported by the observation of large variance in positive affect within the nonexternalizing group. Together, this suggests that the positive feelings of teachers are mainly affected by factors other than externalizing problems. For example, Davis (2006) introduced the concept of relational press to understand the formation of teacher-student relationships. Whether teachers feel pressed by children to develop personal relationships may be a more important factor in the formation of emotionally positive relationships than children's challenging behaviors (cf. New- 
berry \& Davis, 2008). In sum, it could be inferred that teachers' negative affect constitutes the main difference between teacherchild relationships involving disruptive children versus nondisruptive children.

To facilitate the interpretation of our findings, we examined to what degree teachers' narratives could have represented characteristics of the teacher. It is asserted that teachers' mental representations mainly reflect properties of the dyadic relationship with a particular child (Pianta et al., 2003). The results supported this assumption and indicated that the two interviews from the same teachers regarding different pupils yielded distinctive information, especially with respect to teachers' expressed affect. This is in line with research yielding small amounts of betweenteacher variance in closeness and conflict as measured with the STRS in large American and Dutch samples (Mashburn, Hamre, Downer, \& Pianta, 2006; Van Pinxteren, 2008). With respect to the content of the narratives representing sensitive practices, it was found that a substantial proportion of variance could be attributed to features of the teacher. This may point to a personal teaching style that is partly independent of children's characteristics. Furthermore, there was also considerable between-subject variance in teachers' inclination to neutralize negative affect. Thus, there seem to be differences between teachers in how they modulate negative experiences. It should be considered, however, that differences within teachers (i.e., between teacher-child dyads) were overestimated in the current sample because of the sampling method. As a result, teacher effects could have been underestimated. This implies that differences between the narratives regarding the two children may represent global differences in teachers' relationships with typical versus disruptive students. For a more stringent test of the premise that teachers' mental representations predominantly embody properties of the dyadic relationship, it is necessary to replicate findings with randomly selected students.

In conclusion, together with the study from Stuhlman and Pianta (2002), the current research provided compelling evidence for the added value of interview-based methods such as the TRI for research into teacher-child relationships. Whereas Stuhlman and Pianta (2002) examined teachers' narratives in relation to observed teacher-child interactions, we employed teacher reports on a well-validated measure of teacher-child relationships to establish support for the validity of the TRI. In addition, our research extended evidence to an at-risk sample involving children with elevated levels of externalizing behavior. The moderate convergence between the TRI and STRS supports the view that the TRI assesses related but different constructs and adds valuable information about teachers' interpersonal experiences. It should be noted, however, that the sample included mainly ethnically Dutch children and replication in more ethnically diverse samples is needed. In addition, although Dutch kindergarten classes are comparable to those in the United States and other western countries, there may be subtle cultural differences in education and teacher-child interactions that warrant replication in other countries as well.

Several other directions for future research could be considered. Clearly, longitudinal research is needed to establish the predictive value of the TRI for both children's school functioning and teacher-child interactions. Furthermore, the constructs assessed with the TRI were thought to cover three main dimensions of narratives: content, affect, and processing of information. It should be noted, however, that this has not been empirically tested. Although it was beyond the scope of our study, exploratory analyses in both subgroups supported a separate dimension including the content scales but did not support the other key dimensions. Future research could explore the underlying factorial patterns more thoroughly in larger samples. Also, the notion that teachers' narratives reflect mental representations needs to be tested in subsequent research-for instance, with the help of experimental priming methods (cf. Maier et al., 2004). Lastly, we may not have captured all facets of teachers' mental representations of the teacher-child relationship. For example, socialization constituted a more central theme 
in teachers' narratives than academic instruction and learning. These latter themes may become more important in later elementary school (Stuhlman \& Pianta, 2002).

Our research has several limitations that merit attention. As one of the first studies using relationship-focused narratives, this study was largely exploratory in nature and included only a small number of participants. Therefore, replication of findings in larger samples is warranted. Power analyses demonstrated sufficient statistical power (i.e., >.80) to detect medium effects, but samples of approximately 250 teachers and 500 pupils are required for detection of small effects (Snijders \& Bosker, 1999). Furthermore, no causal inferences can be drawn from our data. However, it could be argued that a teacher's mental representation of the relationship with a particular student determines not only the teacher's expression of emotion (e.g., anger) during the interview but also guides the teacher's perception of the student's behavior and degree of conflict in the relationship. Thus it may not be theoretically meaningful to disentangle causality. Lastly, although interrater agreement was acceptable for all scales of the TRI, there are some concerns with respect to the processing area. Relatively high scores were given for the coherence of the narratives, which suggests that the 5-point scale did not discriminate well between the narratives. Interrater reliability for Neutralizing Negative Affect was only fair, which implies that the results for this scale should be considered tentatively.

The TRI seems especially suited to assess more implicit qualities, such as emotional processes and how teachers cope with negative experiences. These insights are particularly relevant for understanding teachers' difficulties in relationships with at-risk students because of behavior problems. Research has consistently demonstrated that children with conduct problems are at risk of school failure and that negative teacher-child relationships may exacerbate this risk (e.g., Hamre \& Pianta, 2001; Ladd \& Burgess, 2001; Silver et al., 2005). Identification of key relational aspects is crucial to understand how to intervene effectively and counteract risks associated with poor social relationships. Together with the research from Stuhlman and Pianta (2002), our findings underline that school psychologists should attend to negative emotional processes of teachers. Encouragement and assistance of teachers to reflect on their negative emotions is considered a promising avenue for enhancing relationship quality. This may not only foster children's school success but may also contribute to teachers' job satisfaction and protect them against stress (Koomen et al., 2007). The TRI actually may provide a starting point for relationship-focused consultation (Koomen et al., 2006; Stuhlman \& Pianta, 2002). Based on the manual, a relational profile reflecting strengths and difficulties can be obtained that is helpful for practitioners who are looking for ways to strengthen teacherchild relationships or who intend to engage in consultation with teachers. How to effectively implement the TRI in teacher-consultation models is a key question that should be addressed in future research.

In summary, our research highlighted the value of teachers' narratives to advance understanding of teacher-child relationships and supported the validity of the TRI as a tool to elicit those narratives. Disruptive children appeared at risk for unfavorable relationships, as shown by elevated levels of teacher conflict, anger, and helplessness. These findings advance scholarly knowledge but also have applied benefits for school psychologists.

\section{References}

Babad, E. (1990). Measuring and changing teachers' differential behavior as perceived by students and teachers. Journal of Educational Psychology, 82, 683-690.

Baker, J. A. (2006). Contributions of teacher-child relationships to positive school adjustment during elementary school. Journal of School Psychology, 44, 211229.

Behar, L. B. (1977). The Preschool Behavior Questionnaire. Journal of Abnormal Child Psychology, 5, 265275.

Birch, S. H., \& Ladd, G. W. (1998). Children's interpersonal behaviors and the teacher-child relationship. Developmental Psychology, 34, 934-946.

Bowlby, J. (1982). Attachment and loss: Vol. 1. Attachment (2nd ed.). New York: Basic Books. (Original work published 1969) 
Bretherton, I. (1985). Attachment theory: Retrospect and prospect. Monographs of the Society for Research in Child Development, 50, 3-35.

Bretherton, I., Biringen, Z., Ridgeway, D., Maslin, C., \& Sherman, M. (1989). Attachment: The parental perspective. Infant Mental Health Journal, 10, 203-221.

Burchinal, M. R., Peisner-Feinberg, E., Pianta, R., \& Howes, C. (2002). Development of academic skills from preschool through second grade: Family and classroom predictors of developmental trajectories. Journal of School Psychology, 40, 415-436.

Button, S., Pianta, R. C., \& Marvin, R. S. (2001). Mothers' representations of relationships with their children: Relations with parenting behavior, mother characteristics, and child disability status. Social Development, 10, 455-472.

Cicchetti, D., Bronen, R., Spencer, S., Haut, S., Berg, A., Oliver, P., et al. (2006). Rating scales, scales of measurement, issues of reliability: Resolving some critical issues for clinicians and researchers. Journal of Nervous and Mental Disease, 194, 557-564.

Davis, H. A. (2006). Exploring the contexts of relationship quality between middle school students and teachers. The Elementary School Journal, 106, 193-223.

Doumen, S., Verschueren, K., \& Buyse, E. (2008, July). Observed teacher-child interactions and teacher perceived relationship quality: Their concordance and associations with school engagement. Paper presented at the 30th ISPA International Conference, Utrecht, The Netherlands.

Doumen, S., Verschueren, K., Buyse, E., Germeijs, V., Luyckx, K., \& Soenens, B. (2008). Reciprocal relations between teacher-child conflict and aggressive behavior in kindergarten: A three-wave longitudinal study. Journal of Clinical Child and Adolescent Psychology, 37, 588-599.

George, C., \& Solomon, J. (1996). Representational models of relationships: Links between caregiving and attachment. Infant Mental Health Journal, 17, 198-216.

Goossens, F. A., Bokhorst, K., Bruinsma, C., \& Van Boxtel, H. W. (2002). Judgments of aggressive, withdrawn and prosocial behavior: Perceived control, anger, pity and sympathy in young Dutch children. Journal of School Psychology, 40, 309-327.

Goossens, F. A., Dekker, P., Bruinsma, C., \& De Ruyter, P. A. (2000). De Gedrags Vragenlijst voor Peuters en Kleuters: Factor structuur, betrouwbaarheid en validiteit. [Behavior questionnaire for 2- to 6-year-olds: factor structure, reliability, and validity]. Amsterdam: Vrije Universiteit.

Hamre, B. K., \& Pianta, R. C. (2001). Early teacher-child relationships and the trajectory of children's school outcomes through eighth grade. Child Development, 72, 625-638.

Hamre, B. K., Pianta, R. C., Downer, J. T., \& Mashburn, A. J. (2008). Teachers' perceptions of conflict with young students: Looking beyond problem behaviors. Social Development, 17, 115-136.

Hargreaves, A. (2000). Mixed emotions: Teachers' perceptions of their interactions with students. Teaching and Teacher Education, 16, 811-826.

Hughes, J. N., Cavell, T. A., \& Jackson, T. (1999). Influence of the teacher-student relationship on childhood conduct problems: A prospective study. Journal of Clinical Child Psychology, 28, 173-184.
Koomen, H. M. Y., Verschueren, K., \& Pianta, R. C. (2007). Leerling Leerkracht Relatie Vragenlijst: Handleiding [Student-Teacher Relationship Scale: Manual]. Houten: Bohn Stafleu van Loghum.

Koomen, H. M. Y., Verschueren, K., \& Thijs, J. T. (2006). Assessing aspects of the teacher-child relationship: A critical ingredient of a practice-oriented psycho-diagnostic approach. Educational and Child Psychology, 23, 50-60.

Ladd, G. W., \& Burgess, K. B. (1999). Charting the relationship trajectories of aggressive, withdrawn, and aggressive/withdrawn children during early grade school. Child Development, 70, 910-929.

Ladd, G. W., \& Burgess, K. B. (2001). Do relational risks and protective factors moderate the linkages between childhood aggression and early psychological and school adjustment? Child Development, 72, 15791601.

Maier, M. A., Bernier, A., Perkrun, R., Zimmermann, P., \& Grossmann, K. E. (2004). Attachment working models as unconscious structures: An experimental test. International Journal of Behavioral Development, 28, 180-189.

Main, M., Kaplan, N., \& Cassidy, J. (1985). Security in infancy, childhood, and adulthood: A move to the level of representation. Monographs of the Society for Research in Child Development, 50, 66-104.

Mashburn, A. J., Hamre, B. K., Downer, J. T., \& Pianta, R. C. (2006). Teacher and classroom characteristics associated with teachers' ratings of prekindergartners' relationships and behaviors. Journal of Psychoeducational Assessment, 24, 367-380.

Meehan, B. T., Hughes, J. N., \& Cavell, T. A. (2003). Teacher-student relationships as compensatory resources for aggressive children. Child Development, 74, 1145-1157.

Murray, C., \& Murray, K. M. (2004). Child level correlates of teacher-student relationships: An examination of demographic characteristics, academic orientations, and behavioral orientations. Psychology in the Schools, 41, 751-762.

Newberry, M., \& Davis, H. A. (2008). The role of elementary teachers' conceptions of closeness to students on their differential behavior in the classroom. Teaching and Teacher Education, 24, 1965-1985.

O'Connor, E., \& McCartney, K. (2007). Examining teacher-child relationships and achievement as part of an ecological model of development. American Educational Research Journal, 44, 340-369.

Palermo, F., Hanish, L. D., Martin, C. L., Fabes, R. A., \& Reiser, M. (2007). Preschoolers' academic readiness: What role does the teacher-child relationship play? Early Childhood Research Quarterly, 22, 407-422.

Pianta, R. C. (1999a). Assessing child-teacher relationships. In R. C. Pianta, Enhancing relationships between children and teachers (pp. 85-104). Washington, DC: American Psychological Association.

Pianta, R. C. (1999b). The emotional bond between children and adults. In R. C. Pianta, Enhancing relationships between children and teachers (pp. 65-83). Washington, DC: American Psychological Association.

Pianta, R. C. (2001). Student-Teacher Relationship Scale. Professional manual. Lutz, FL: Psychological Assessment Resources. 
Pianta, R. C., Hamre, B., \& Stuhlman, M. (2003). Relationships between teachers and children. In I. B. Weiner (Series Ed.) \& W. M. Reynolds \& G. E. Miller (Vol. Eds.), Handbook of psychology: Educational psychology (Vol. 7, pp. 199-234). Hoboken, NJ: John Wiley \& Sons

Pianta, R. C., Steinberg, M. S., \& Rollins, K. B. (1995). The first two years of school: Teacher-child relationships and deflections in children's classroom adjustment. Development and Psychopathology, 7, 295-312.

Pianta, R. C., \& Stuhlman, M. W. (2004). Teacher-child relationships and children's success in the first years of school. School Psychology Review, 33, 444-458.

Rasbash, J., Browne, W., Healy, M., Cameron, B., \& Charlton, C. (2005). MLwiN Version 2.02 [Computer software]. New York: Multilevel Models Project Institute of Education.

Silver, R. B., Measelle, J. R., Armstrong, J. M., \& Essex, M. J. (2005). Trajectories of classroom externalizing behavior: Contributions of child characteristics, family characteristics, and the teacher-child relationship during the school transition. Journal of School Psychology, 43, 39-60.

Snijders, T. A. B., \& Bosker, R. J. (1999). Multilevel analysis: An introduction to basic and advanced multilevel modeling. London: Sage.

Solomon, J., \& George, C. (1999). The caregiving system in mothers of infants: A comparison of divorcing and married mothers. Attachment and Human Development, 1, 171-190.

Stuhlman, M. W., \& Pianta, R. C. (2002). Teachers' narratives about their relationships with children: As- sociations with behavior in classrooms. School Psychology Review, 31, 148-163.

Thijs, J. T., Koomen, H. M. Y., De Jong, P. F., Van der Leij, A., \& Van Leeuwen, M. G. P. (2004). Internalizing behaviors among kindergarten children: Measuring dimensions of social withdrawal with a checklist. Journal of Clinical Child and Adolescent Psychology, 33, 802-812.

Thijs, J. T., Koomen, H. M. Y., \& Van der Leij, A. (2006). Teachers' self-reported pedagogical practices toward socially inhibited, hyperactive, and average children. Psychology in the Schools, 43, 635-651.

Thijs, J. T., Koomen, H. M. Y., \& Van der Leij, A. (2008). Teacher-child relationships and pedagogical practices: Considering the teacher's perspective. School Psychology Review, 37, 244-260.

Van Pinxteren, E. (2008). Juffen en meesters: Genderverschillen in de beleving van de leerkracht-leerlingrelatie in het primair onderwijs. [Female and male teachers: gender differences in perceptions of the teacherchild relationship in primary education]. Unpublished manuscript, University of Amsterdam, Amsterdam.

Zeller, J. J. (2004). Teachers' childhood attachments and teacher-student relationships. Dissertation Abstracts International: Section B: The Sciences and Engineering, 65, 2120 .

Date Received: June 27, 2008

Date Accepted: December 20, 2008

Action Editor: Shane Jimerson

\section{Appendix \\ Overview of Scales Teacher Relationship Interview (TRI)}

Rating Scale

Sensitive

Discipline

Secure Base

Perspective

Taking

Intentionality

Positive Affect

Helplessness

Anger

Neutralizing

Negative Affect

Coherence
Description

The teacher is sensitive and proactive in his/her management style.

The teacher understands that his/her emotional support is linked to the child's social, emotional, and cognitive skills.

The teacher is aware of the student's internal states, and provides possible reasons for that state.

The teacher seeks opportunities to promote the student's growth in either socialemotional or academic domains.

The teacher expresses positive feelings, including happiness, closeness, joy, love, pride, etc.

The teacher expresses feelings of hopelessness and ineffectiveness, and refrains from new strategies.

The teacher expresses feelings of anger, hostility or disapproval towards the child.

The teacher avoids discussing negative emotions.

The teacher presents experiences in a reasonable and understandable manner.

Note. The TRI coding manual can be found on the website of the University of Virginia Center for Advanced Study of Teaching and Learning (CASTL): http://www.virginia.edu/vpr/CASTL/resources/tri.php 
Jantine L. Spilt, $\mathrm{PhD}$ (cand), is a doctoral candidate in special education in the Faculty of Social and Behavioral Sciences at the University of Amsterdam. Her research interests include teacher-student relationships and teachers' pedagogical practices in relation to emotional well-being and especially externalizing behavior of young children.

Helma M. Y. Koomen, $\mathrm{PhD}$, is an assistant professor in special education in the Faculty of Social and Behavioral Sciences at the University of Amsterdam. Her research interests address student-teacher interactions and teachers' pedagogical practices in relation to emotional well-being, social adjustment, and task behaviors. 
Copyright of School Psychology Review is the property of National Association of School Psychologists and its content may not be copied or emailed to multiple sites or posted to a listserv without the copyright holder's express written permission. However, users may print, download, or email articles for individual use. 